\section{Kuhmilchsensibilisierung bereits in utero}

\author{
Bei atopischen Neugeborenen können in den mononukleären Zellen \\ des Nabelschnurbluts Antigen-spezifische Antworten z. B. auf Haus- \\ staubmilben nachgewiesen werden. Eine Studie versuchte Einblicke \\ in die Sensibilisierung gegen Kuhmilchproteine zu gewinnen.
}

$\mathrm{P}$ ädiater der Universität Graz untersuchten die Reaktivität von mononukleären Zellen aus dem Nabelschnurblut (CBMC) von Neugeborenen gegenüber Kuhmilchproteinen, nachgewiesen mit dem ELISPOT-Assay. Einbezogen waren die Neugeborenen von atopischen und nicht atopischen Müttern.

In Übereinstimmung mit anderen Studien war bei den fristgerecht entbundenen Kindern die spontane Zytokinfreisetzung aus den CBMC dominiert von IL-4, IL-5, IL-10 und von TGF- $\beta$. Dieses Zytokin wurde von den Kindern atopischer Mütter als einziges in weniger starkem Umfang freigesetzt, möglicherweise aufgrund eines TH3-Zelldefizits bei diesen Kindern.

Bei der In-vitro-Stimulation der CBMC mit verschiedenen Kuhmilch- proteinen dominierte bei der Zytokinsekretion die TH2-Antwort. Interessanterweise zeigten die Kinder der atopischen Mütter eine schwächer ausgeprägte TH2-Antwort als die Kinder nicht atopischer Mütter - signifikant nachgewiesen für IL- 4 und TGF- $\beta$. Für diesen überraschenden Befund liefert die Studie zunächst keine Erklärung. Bei Kindern, die vor der 35. Schwangerschaftswoche geboren wurden, ließen sich weder spontane noch Kuhmilchprotein-assoziierte Antworten induzieren.

Für die nähere Charakterisierung der Zytokin sezernierenden Zellen wurden die naiven CD4+CD45RA-Zellen und die CD4+CD45RO-Memory-TZell-Subpopulation isoliert und auf ihre spontane bzw. durch Kuhmilchprotein induzierbare Zytokinfreisetzung hin untersucht. Auch wenn die Antworten nur sehr schwach waren, zeigten die CD45RO+-Zellen der Kinder von atopischen Müttern signifikante Antigenspezifische IL-4- und TGF- $\beta$-Antworten, die CD45RA+-Zellen ergaben erniedrigte IL-4- und vor allem reduzierte TGF- $\beta$-Antworten. Dagegen ließ sich bei den Zellen der Kontrollkinder praktisch keine Reaktion nachweisen.

Fazit: Bestimmte Gedächtniszell-Subpopulationen aus dem Nabelschnurblut von Kindern atopischer Mütter zeigen eine spezifische IL-4- und TGF- $\beta$-Antwort auf die Stimulation mit Kuhmilchprotein. Dies weist auf eine Verschiebung zugunsten der TH2-Antwort bei der Reaktion auf Nahrungsmittelantigene bereits in utero hin.

$b k$

Hauer AC et al. Cytokine production by cord blood mononuclear cells stimulated with cows milk proteins in vitro: interleukin-4 and transforming growth factor $\beta$-secreting cells detected in the CD45RO T cell population in children of atopic mothers. Clin Exp Allergy 2003; 33: 615-23

\title{
Kratzen als Immunmodulator?
}

\section{Das atopische Ekzem ist eine initial TH2-Zytokin-dominierte Haut- erkrankung. Zu den wichtigsten Symptomen gehört Hautjucken, auf das die Patienten mit Kratzen reagieren. Modulieren sie durch dieses Verhalten möglicherweise ihre Immunantwort?}

D urch einen Versuch an Mäusen sollte untersucht werden, ob Kratzen die Immunantwort auf eine epikutane Sensibilisierung modifiziert. Dazu wurden die Mäuse am Bauch rasiert und dort zehnmal mit einer Drahtbürste gestriegelt. Dann wurden sie über 5 Wochen wiederholt mit dem Hämocyanin der Schlüssellochnapfschnecke per Okklusivpflaster sensibilisiert. Während dieser Zeit bestimmten die Forscher verschiedene Immunparameter. Als Kontrolle dienten nicht gebürstete Mäuse.

Die Kontrollmäuse zeigten eine TH2-dominierte Immunantwort mit einer vermehrten Bildung von IL-13 in der Haut und erhöhtem spezifischem $\mathrm{IgE}$ im Serum. Bei den vorher mit einer Drahtbürste behandelten Mäusen lag dagegen eine TH1-dominierte Immunantwort vor. Sie zeigten eine verzögerte Hypersensitivitätsreaktion der Haut, was vom Pathomechanismus her dem allergischen Kontaktekzem entspricht und eine überwiegend über Langerhanszellen vermittelte TH1-Reaktion darstellt. Außerdem stiegen bei ihnen die Antigen-spezifischen IgG2a- und IgG2b-Spiegel, nicht aber das IgE im Serum. In der Haut dieser Mäuse fanden sich hohe Konzentrationen des TH1-Zytokins IFN- $\gamma$, die Spiegel des
TH2-Zytokins IL-13 waren dagegen normal.

Wie es zu dieser unterschiedlichen Immunantwort kommen kann, ist unklar. Entscheidend scheint aber die durch das Bürsten hervorgerufene Hautläsion zu sein. Dadurch können höhere Allergendosen an die lokalen Immunzellen gelangen, was bevorzugt eine TH1-Antwort auslöst. Auch ist bekannt, dass eine Störung der Hautbarriere zur Produktion von bestimmten Zytokinen führt, die letztlich die Langerhanszellen bzw. TH1-Zytokine aktivieren.

Fazit: Kratzen der Haut moduliert bei Mäusen die Immunantwort auf eine kutane Sensibilisierung in Form eines Switch zu TH1.

Matsushima $\mathrm{H}$ et al. Skin scratching switches immune responses from Th2 to Th1 type in epicutaneously immunized mice. J Dermatol Sci 2003; 32: 223-30 